\title{
North East Pacific Time-Integrated Undersea Networked Experiments (NEPTUNE): Cable Switching and Protection
}

\author{
Mohamed A. El-Sharkawi, Fellow, IEEE, Aditya Upadhye, Shuai Lu, Harold Kirkham, Senior Member, IEEE, \\ Bruce M. Howe, Tim McGinnis, and Phil Lancaster
}

\begin{abstract}
The objective of the North East Pacific Time-Integrated Undersea Networked Experiments (NEPTUNE) is to establish a permanent, subsea observatory surrounding the Juan de Fuca tectonic plate. To achieve this objective, a special power distribution system is designed to provide continuous power to science equipment, vehicles, and laboratories located as deep as $5 \mathrm{~km}$ below the water surface. The NEPTUNE power system is significantly different from terrestrial power systems in many aspects and it requires different switching, protection, and control strategies. In this paper, we address the design of system switching and fault isolation equipment.
\end{abstract}

Index Terms-Circuit breakers, fault diagnosis, power electronics, transient analysis, underwater cables.

\section{INTRODUCTION}

$\mathbf{T}$ HE vast oceans of the world have not yet been explored completely [1]. Present technology allows the deployment of battery-operated instruments, low-power instruments powered from shore, autonomous underwater vehicles (AUVs), or remotely operated vehicles (ROVs) that can explore the deep ocean floor and carry out scientific experiments. All of these methods are power-constrained. In shallow waters, the ROV is powered by a generating unit on the ship through a flexible marine cable. However, the cable weight and length makes the operation of the ROV in deep waters an extremely difficult task. An alternative method is to outfit the ROV with batteries. However, the weight, volume, and the limited energy storage capacity of the batteries restrict the mission of the ROVs to short periods. Carrying out scientific experiments on the ocean floor for extended time is a challenging task that demands a permanent source of energy to create a permanent observatory. This is the main task of the power system design of NEPTUNE.

The topology of the planned North East Pacific Time-Integrated Undersea Networked Experiments (NEPTUNE) power

Manuscript received September 22, 2003; accepted August 26, 2004. This work was sponsored by the National Science Foundation by Grant OCE 0116750 "Development of a Power System for Cabled Ocean Observatories." Associate Editor: J. Lynch.

M. A. El-Sharkawi, A. Upadhye, and S. Lu are with the Department of Electrical Engineering, University of Washington, Seattle, WA 98195 USA (e-mail: elsharkawi@ee.washington.edu).

H. Kirkham is with the Jet Propulsion Laboratory, California Institute of Technology, Pasadena, CA 91109 USA.

B. M. Howe and T. McGinnis are with the Applied Physics Laboratory, University of Washington, Seattle, WA 98195 USA.

P. Lancaster is with Alcatel Submarine Network, Greenwich, SE10 0AG London, U.K.

Digital Object Identifier 10.1109/JOE.2004.839938 system is shown in Fig. 1. It is a fiber-optic/power cable network around and across the Juan de Fuca tectonic plate off the west coast of North America [2]. The NEPTUNE power system consists of a backbone circuit that covers the entire service area, and branching circuits to reach specific sites. The backbone network is comprised of $3000 \mathrm{~km}$ of cable connecting about 30-40 evenly distributed branching units (BU). The red circles in Fig. 1 show some of the system BUs. These BUs can be viewed as the switching yards in terrestrial systems. The branching circuits are not shown in the figure, but they are cables connecting the BUs to the load nodes on the seafloor. The length of the branching cables can be as long as $100 \mathrm{~km}$. Each node provides standard power to the scientific equipment, and internet communication interfaces between the scientific equipment and shore. The communication network has a capacity of about $10 \mathrm{~Gb} / \mathrm{s}$, and the power network delivers $200 \mathrm{~kW}$ with a design life of $25 \mathrm{yr}$ [3].

The main design features of NEPTUNE power system are as follows.

1) The total capacity of the network is $200 \mathrm{~kW}$ provided by two shore stations: one will be located on Vancouver Island, Canada; and the other on the Oregon coast, USA. Each of these stations is capable of providing $100 \mathrm{~kW}$. A redundant power supply will be located at each of the shore stations.

2) The cable will have a voltage rating of $10 \mathrm{kV}$. The resistance of telecom cable is around $1 \Omega / \mathrm{km}$, so that for high currents and distances of a few hundred $\mathrm{km}$, the cable volt-drop can approach the voltage rating of the cable. Hence, a current rating of $10 \mathrm{~A}$ has been set for the power network.

3) The submarine cable is to be selected from among the existing conventional submarine telecommunications cables. This is done to reduce the cost of the backbone system. The conventional submarine cables are highly reliable and are being used in subsea telecom systems all over the world. Fig. 2 shows one of the proposed cables. The cable is to serve a dual purpose; its hollow core carries fiber optics for communications, and its copper sheath is used to transmit the electric power.

4) The cable network is dc to reduce the effect of cable capacitance [4].

5) The ocean provides the return path for the current, so a single conductor cable can be used.

6) The anode of the system must be at the shore station to limit the corrosion of the equipment in deep water. Hence, 


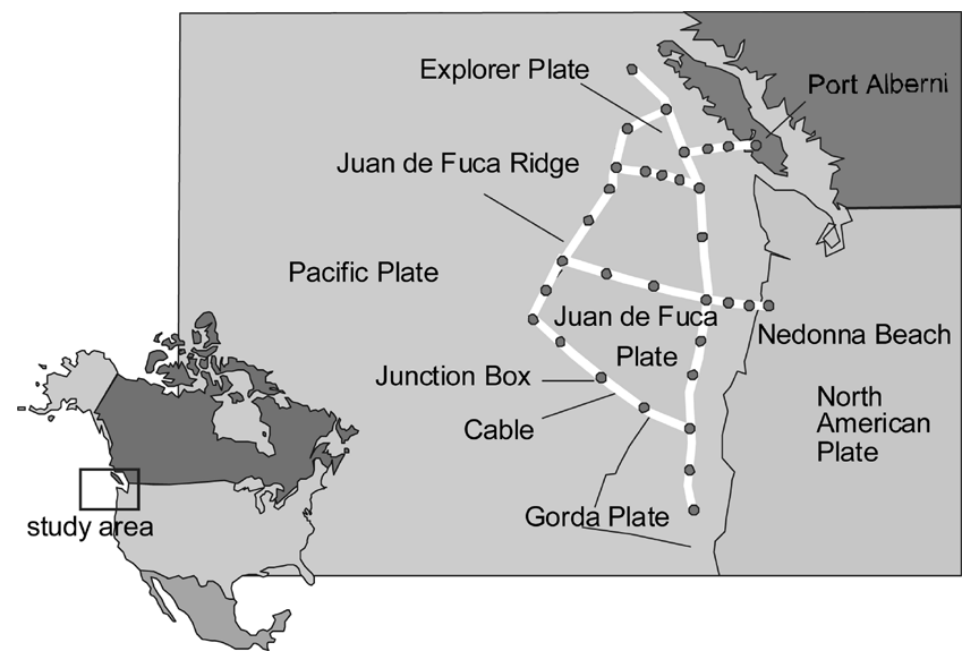

Fig. 1. NEPTUNE cable system.

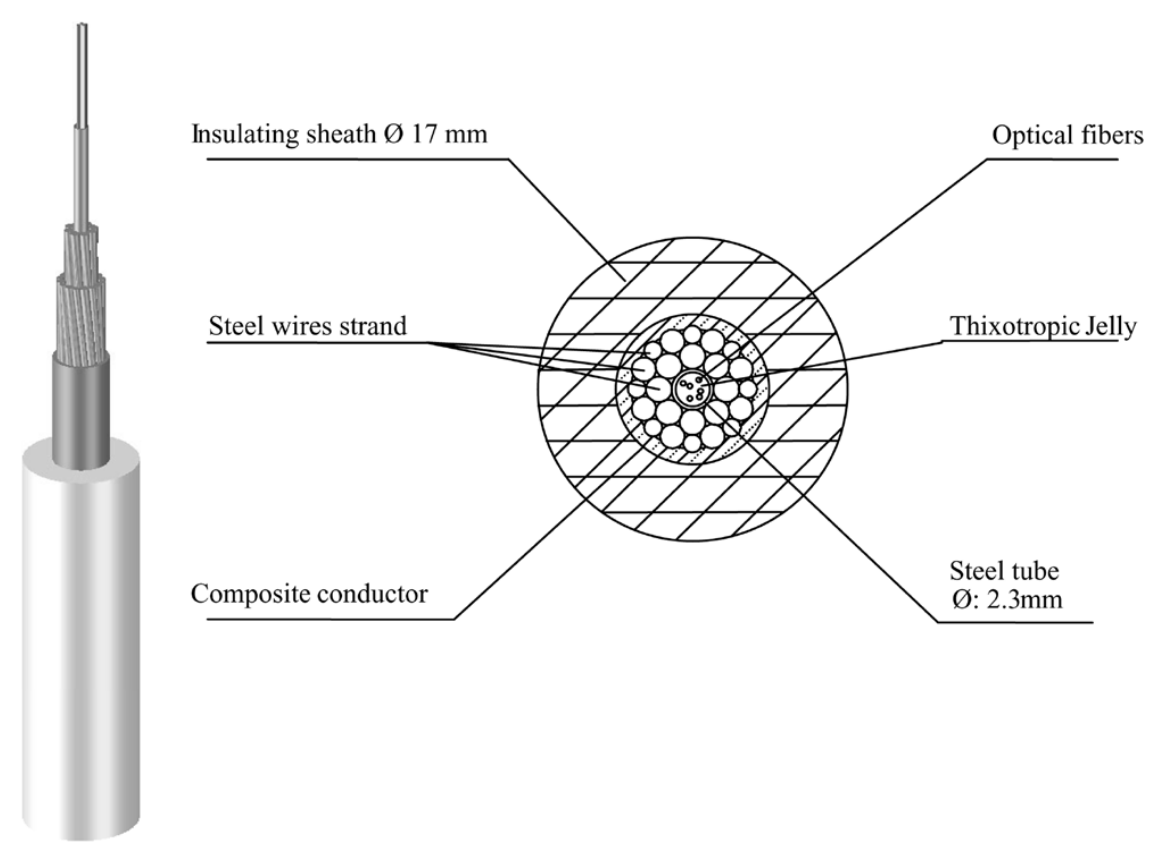

Fig. 2. Proposed cable for the NEPTUNE observatory.

the voltage of the shore station is negative with respect to ground.

7) At each node, a dc-dc converter is to be used to reduce the incoming voltage from $10 \mathrm{kV}$ to a more conventional level of $400 \mathrm{~V}$.

8) In the event of component failures or cable fault, a protection system isolates the fault as soon as possible and minimizes the loss of load.

9) If a fault occurs, its location must be identified to within $1 \mathrm{~km}$ to minimize the cost of search and repair in deep water.

In this paper, we address the design of the switching and protection circuits of NEPTUNE. To our knowledge, there is no dc mesh network in operation. Most, including the well-known dc system designed by Thomas Edison, were radial systems, or point-to-point. Direct current in mesh network structures has not been fully studied for terrestrial systems, and certainly has not been considered for submarine systems.

\section{Switching And SEctionalizers: Two Design CONCEPTS}

The NEPTUNE network consists of several BU/node combinations connected by submarine cables as shown in Fig. 1. We have considered two conceptual designs for the BUs and nodes; Version 1 is shown in Fig. 3, and version 2 in Fig. 4.

In Version 1, the backbone cable is routed to the science node through passive BUs commonly used in submarine cables. The $\mathrm{BU}$ in this design has no switching element and is used as a branching box. The power is delivered to the node using two spur cables that could be as long as $100 \mathrm{~km}$ each. The node, however, contains the switching devices (breakers) necessary to isolate cable faults, the dc-dc converters, the communication circuits, and the control circuitry. The controller in charge of switching is powered by the dc-dc converter of the node. The diodes are used to ensure that the dc-dc converter of the node is powered first before any switching action is employed to connect the rest of the network. This feature is explained in more detail later in the paper. 


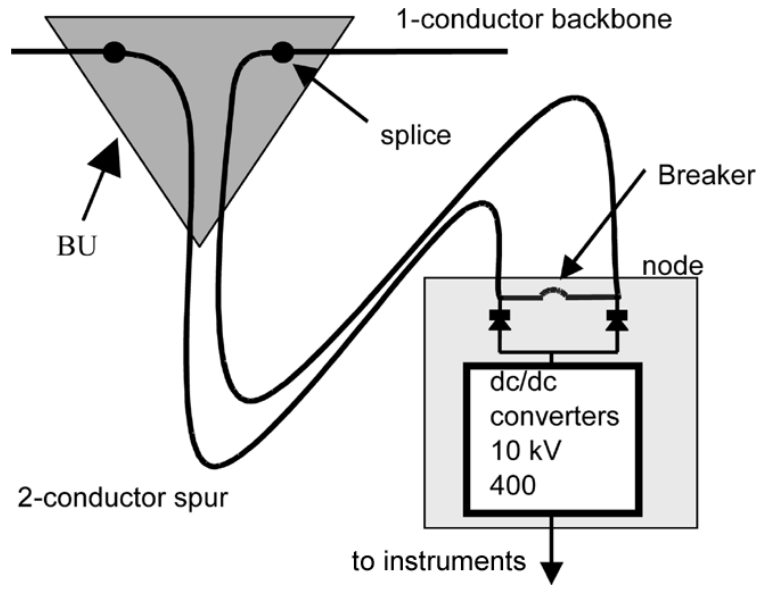

Fig. 3. Version 1 power system design.

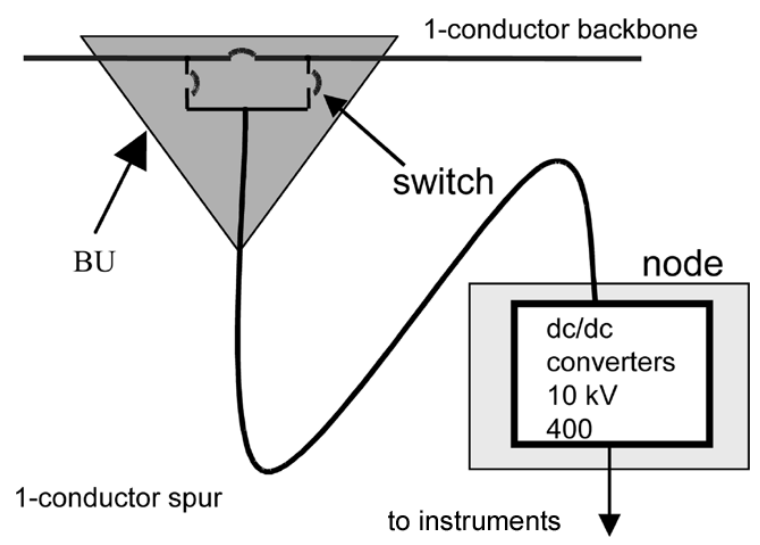

Fig. 4. Version 2 power system design.

In Version 2, active BUs house the switching devices (breakers) and their controllers. The dc-dc converters and the communication circuits are located in the science node. The node is powered through a single conductor spur cable from the BU. In this active BU system, the power of the controller is tapped from the backbone cable, and is not dependent on the dc-dc converter. This design is explained in more detail in Sections II-A and B.

There are several merits and demerits for each design. The key comparative features are shown in Table I.

In either version, a circuit breaker must be designed to interrupt the dc current. Because there are no naturally occurring current zeroes in dc, interrupting the current is a nontrivial process.

Two switching concepts are studied in this paper. The first one is to locate a dc circuit breaker in the node. The breaker is composed of several elements to force a current zero by diverting the electrical energy to a storage capacitor. By proper design, arcing and restrikes can be substantially reduced or eliminated. This approach is the one taken in Version 1 design.

Another approach is based on the fact that faults in submarine cables are rare and will likely only happen a few times over the design life of the project (25 years). Most of the cables are in deep water where faults due to fishing accidents or anchoring are virtually nonexistent. Nevertheless, if a fault occurs, shutting down the entire system from the shore stations is justifiable, providing a sequential reenergization and isolation of the fault
TABLE I

COMPARISON OF KEY ISSUES IN VERSIONS 1 AND 2

\begin{tabular}{|c|c|}
\hline Version 1 & Version 2 \\
\hline $\begin{array}{l}\text { All backbone breakers } \\
\text { depend on node operation. } \\
\text { Hence, a single node } \\
\text { failure can cause failure to } \\
\text { large sections of the } \\
\text { network. }\end{array}$ & $\begin{array}{l}\text { Any node failure can be } \\
\text { isolated, and the rest of the } \\
\text { network maintains its } \\
\text { functions. }\end{array}$ \\
\hline $\begin{array}{l}\text { A failed dc-dc converter in } \\
\text { the node can interrupt the } \\
\text { controller's power supply } \\
\text { operating the breakers. }\end{array}$ & $\begin{array}{l}\text { The breaker controller is } \\
\text { independent of the dc-dc } \\
\text { converter. }\end{array}$ \\
\hline $\begin{array}{l}\text { Fault current is interrupted } \\
\text { by the node breaker; arcing } \\
\text { and restrikes should be } \\
\text { prevented }\end{array}$ & $\begin{array}{l}\text { Fault current is interrupted } \\
\text { at the shore stations; arcing } \\
\text { and restrikes are avoided in } \\
\text { the sub-sea system }\end{array}$ \\
\hline $\begin{array}{l}\text { There is communication } \\
\text { between nodes, and } \\
\text { between BUs and shore. } \\
\text { Hence, the breakers can be } \\
\text { fully controlled by the } \\
\text { operator }\end{array}$ & $\begin{array}{l}\text { The BUs have no } \\
\text { communication links. The } \\
\text { operation of the switches } \\
\text { in the BUs are thus } \\
\text { autonomous. }\end{array}$ \\
\hline $\begin{array}{l}\text { Two-conductors in the } \\
\text { spur cable are used, which } \\
\text { implies a costly special } \\
\text { cable. }\end{array}$ & $\begin{array}{l}\text { Single spur is used. It is a } \\
\text { cheaper option. }\end{array}$ \\
\hline
\end{tabular}

can be done in a short time. In this case, interrupting the fault can be done at the shore stations. The node switching is done only under normal operating conditions, or at substantially reduced voltage. This approach is reflected in Version 2 design.

\section{A. Version 1: Design of the DC Circuit Breaker}

The design of the node breaker of Version 1 is shown in Fig. 5. The components in the outer box are all located inside the node. The main elements are

- four vacuum switches: S1, S2, S3, and S4. The advantages of vacuum interrupters in medium voltage applications are widely recognized [5], [6]. All vacuum switches are normally open type.

- Soft-closing resistor R1.

- Bypass capacitor C.

- Discharging resistor Rd.

- Two diodes.

- Controller for the solenoids of the vacuum switches (C1 to C4).

- Back-to-back zeners to provide low voltage power to the communication repeaters.

- Snubbing inductors on both ends of the spur cables to protect the communication repeaters from high frequency current transients.

In this design, all the switching devices in the node are energized by the dc-dc converter. Hence, the converter must be powered first before any switching action is made. To achieve this, two diodes are used as shown in the figure. As aforementioned, the voltage of the shore stations is negative with respect to ground (ocean). After one of the shore stations is switched on, the diodes of the first node energize the converter regardless which side of the node is powered first. The converter 


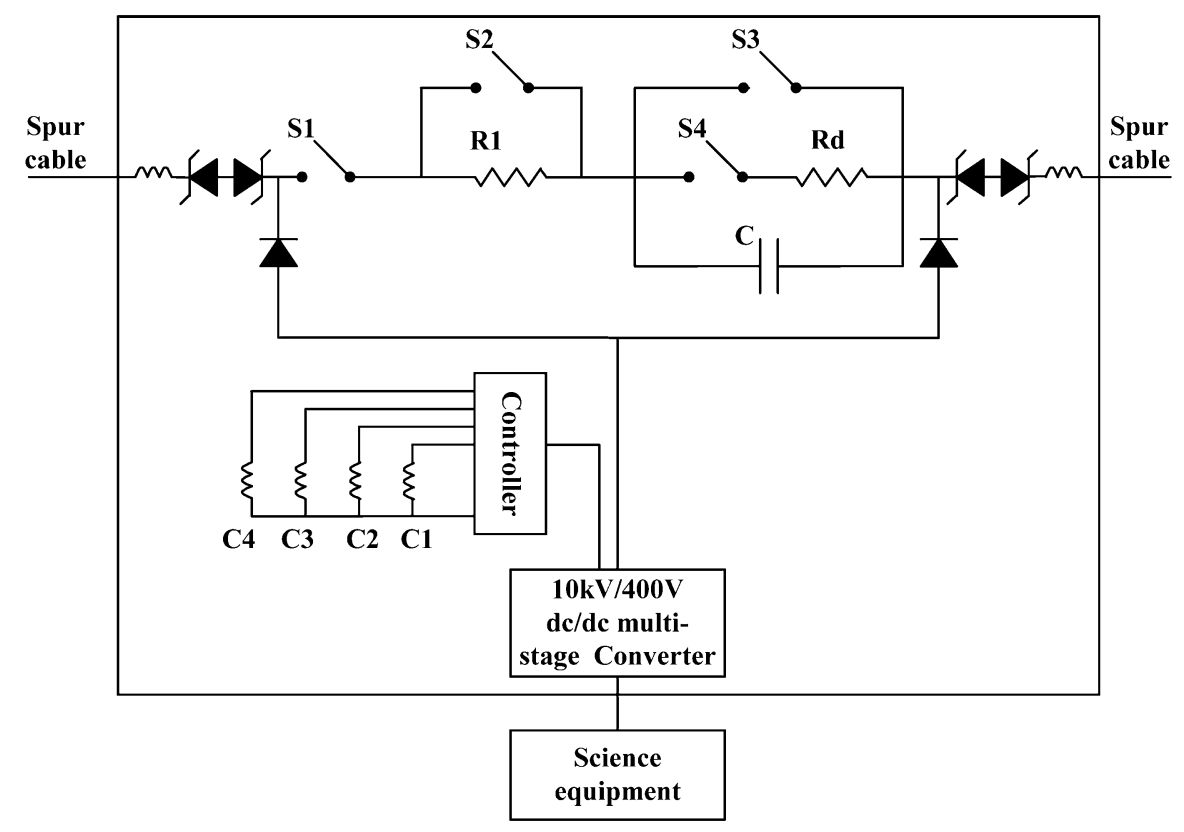

Fig. 5. Version 1 circuit breaker.

then powers the controller of the vacuum switches. The node controller, upon a command from NEPTUNE control center, closes the node switches in a sequence described later. After the switches of the first node are closed, the converter of the next node is energized and the process is repeated sequentially until the backbone cables are fully connected. The NEPTUNE control center is located on shore and has full control of the switching, protection and control actions of the nodes. The software exercising the control is known as the Power Management and Control System (PMACS) [7]. PMACS relies on full communication with all nodes through the fiber optics located inside the submarine cable.

1) Closing Process: All vacuum switches are normally open type. When the node controller receives a closing command from PMACS, it initiates the following steps:

Step 1) S3 is closed first. No current flows in the branch between the two diodes.

Step 2) S1 is closed to energize the cable of the Section II-A2. The soft closing resistance R1 is now in the circuit to reduce the inrush current due to charging the cable capacitance.

Step 3) Remove R1 by closing S2. The soft closing resistor is in the circuit for less than $1 \mathrm{~s}$, and its energy dissipation is manageable. The closing switching sequence is complete.

2) Opening Process: The opening operation is more complex since it must be made without restrikes. Unlike ac systems, interrupting dc currents cannot coincide with natural zero crossings. In this case, the dc current must be driven to zero using external circuits before the switch is fully open. One method to achieve this is to design a bypass circuit by which the current can be rerouted into a series capacitor. The capacitor current then decays exponentially to zero. Before interrupting current, the three switches S1, S2, and S3 are closed. Upon receiving an "open" command, the controller of the breaker initiates the following switching sequence:
Step 1) S3 opened to commutate the current to the capacitor C. During the charging process, the current of the cable is reduced exponentially. Once fully charged, the capacitor has fully interrupted the current of the cable.

Step 2) Once the current is brought close to zero, switch $\mathrm{S} 1$ is opened and the circuit breaker can be regarded as fully opened.

Step 3) To reset the breaker for the next switching action, the capacitor is discharged. This is done by closing S4, while the other switches are open. The capacitor is discharged through the resistor $\mathrm{Rd}$ whose magnitude determines the discharging time of the capacitor.

The components in Fig. 5 are selected to achieve the following:

1) Soft starting during the closing process by inserting the correct value of resistance R1. The resistance should be in the circuit for a short time to reduce the energy losses and the size of the resistor.

2) To prevent restrikes from occurring inside the vacuum switches. Restrikes can damage the vacuum switches especially when repeated.

Restrike is a phenomenon that may occur while the circuit breaker is opening. As the breaker's electrodes separate, the dielectric medium of the circuit breaker begins to regain its strength and the withstanding voltage of the breaker increases. Simultaneously, the voltage across the switch contacts builds up in accordance with the nature of the switching event and the parameters of the entire system. If voltage buildup exceeds the withstanding voltage at any instant, an interelectrode breakdown occurs and arc current is produced. This is known as restrike. For any given mechanical switch, with fixed opening acceleration, only the rate of rise of the restrike voltage (RRRV) can be controlled to prevent restrikes. 


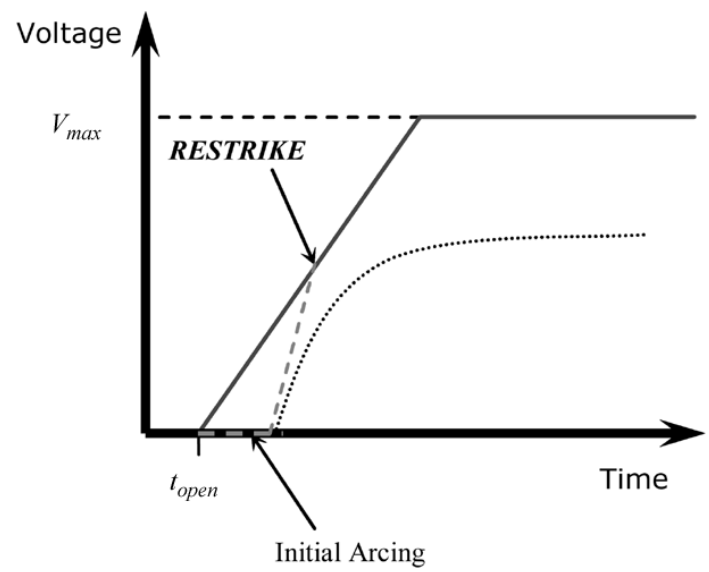

Fig. 6. Voltage buildup and restrike.

TABLE II

RESTRIKE STUDIES

\begin{tabular}{c|c|c}
\hline $\begin{array}{c}\text { Maximum } \\
\text { switch } \\
\text { voltage } \\
(\mathrm{KV})\end{array}$ & $\begin{array}{c}\text { Travel time } \\
\text { of switch } \\
(\mathrm{ms})\end{array}$ & $\begin{array}{c}\text { Minimum value of } \\
\text { capacitance to } \\
\text { prevent restrikes }(\mu \mathrm{F})\end{array}$ \\
\hline \hline 15 & 5 & 2 \\
\hline \hline 15 & 10 & 5 \\
\hline \hline 15 & 18 & 10 \\
\hline 25 & 15 & 1 \\
\hline 25 & 18 & 1 \\
\hline 25 & 20 & 1 \\
\hline
\end{tabular}

Fig. 6 illustrates the restrike phenomenon. The curved lines represent the restrike voltage in the case that the external circuit is well damped. The solid line represents the withstanding voltage, for schematic purpose, which is assumed to increase linearly to the insulation level of the breaker $\left(V_{\max }\right)$. The dotted line represents a case where the voltage buildup across the breaker's contacts never exceeds the withstanding voltage of the breaker. Thus restrike does not occur. The dashed curve represents the case where the external system parameters cause the voltage buildup to exceed the withstanding voltage, and restrike occurs. In the event of a restrike, high $d v / d t$ may be produced (especially if the external circuit is not damped), along with destructive power dissipation in the breaker. These effects have the potential to damage loads, cables and equipment.

To eliminate restrikes in Version 1, three parameters in the dc breaker configuration of Fig. 5 are selected to ensure that the withstanding voltage is always higher than the voltage buildup across the breaker. These three parameters are the size of the bypass capacitor, the speed of the vacuum interrupter, and the maximum withstanding voltage of the vacuum interrupter. The size of the capacitor determines the rate at which the voltage across the vacuum interrupter builds up during the opening process. The speed of the vacuum interrupter and its maximum withstanding voltage determine the slope by which the withstand voltage increases. Table II shows various values of the three parameters that prevent restrikes, using vacuum breakers from a well-known manufacturer. If a small size capacitor is used, fast and high voltage vacuum switches should be selected. In all cases shown in Table II, we assume that the initial large fault current has passed and the circuit breaker clears the steady-state fault current, which is limited to $10 \mathrm{~A}$ by the shore stations. In addition, to reduce the size of the capacitors, the initial arcing may occur and is tolerated. To prevent initial arcing, larger capacitors must be used.

\section{B. Version 2: Active Branching Unit}

In Version 2, the branching unit is active, i.e., it houses the high voltage switching circuit and its sensing devices (e.g., a resistive voltage divider is used to sense the line voltage). The node in this design still houses the dc-dc converter, communication equipment, sensing devices and low voltage switching and protection, but it does not communicate with the BU.

The switching circuit in version 2 does not interrupt fault currents. The main reason for this choice is reliability of switching, but it is worth noting that the space available in commercial BUs is very limited and cannot easily accommodate the extra components for fault clearing. Fault clearing functions are left to the shore stations as explained later. Also in this design, there are no explicit communication links between PMACS and the BU circuits. Hence, the switching circuit in Version 2 must be autonomous, with enough intelligence to identify the intended operation and protection protocols. The science node, however, has communication links with shore and PMACS.

The main components of the switching circuit in version 2 are shown in Fig. 7. The circuit consists of the following key components.

- Four latch-type vacuum switches arranged as shown in the figure. Each switch has two operating solenoids; one for closing $(\mathrm{C})$ and one for opening $(\mathrm{O})$.

- Back-to-back zeners on each side of the switching circuit to operate as low voltage power supply for the BU controller and the communication repeaters.

- Opening solenoids (O1 and $\mathrm{O} 3$, or $\mathrm{O} 2$ and $\mathrm{O} 4)$ of two switches (S1 and S3, or S2 and S4), each pair operated by one BU controller.

- Two closing circuits; each consists of the closing solenoids (C1 and $\mathrm{C} 3$, or C2 and C4) of two switches (S1 and S3, or S3 and S4), a capacitor, a silicon diode for alternating current (SIDAC), a diode, and a resistance.

The BU switching circuit is autonomous and can perform five basic operations without external intervention: startup, normal, faulted, fault locating, and fault isolation modes. In all these modes, the BU cannot communicate with the shore stations or PMACS through the fiber optic cables. Therefore, we used various settings for the shore station voltage as a means to communicate information to the $\mathrm{BU}$ about the intended mode of operation. These operations are discussed in Sections II-B1-4.

1) Start Up Mode: The purpose of the startup mode is to close and latch all switches. In normal operation, the shore station voltage is a negative $10 \mathrm{kV}$. During the startup mode, the shore station voltage is set to a lower positive voltage of $500 \mathrm{~V}$. The voltage reduces the inrush current when closing the switches, thus eliminating the need for current limiting resistances at the startup. Assume that the shore station is at the left side of the BU in Fig. 7. Since the voltage is positive, the diode in the closing branch at the left side allows the capacitor 


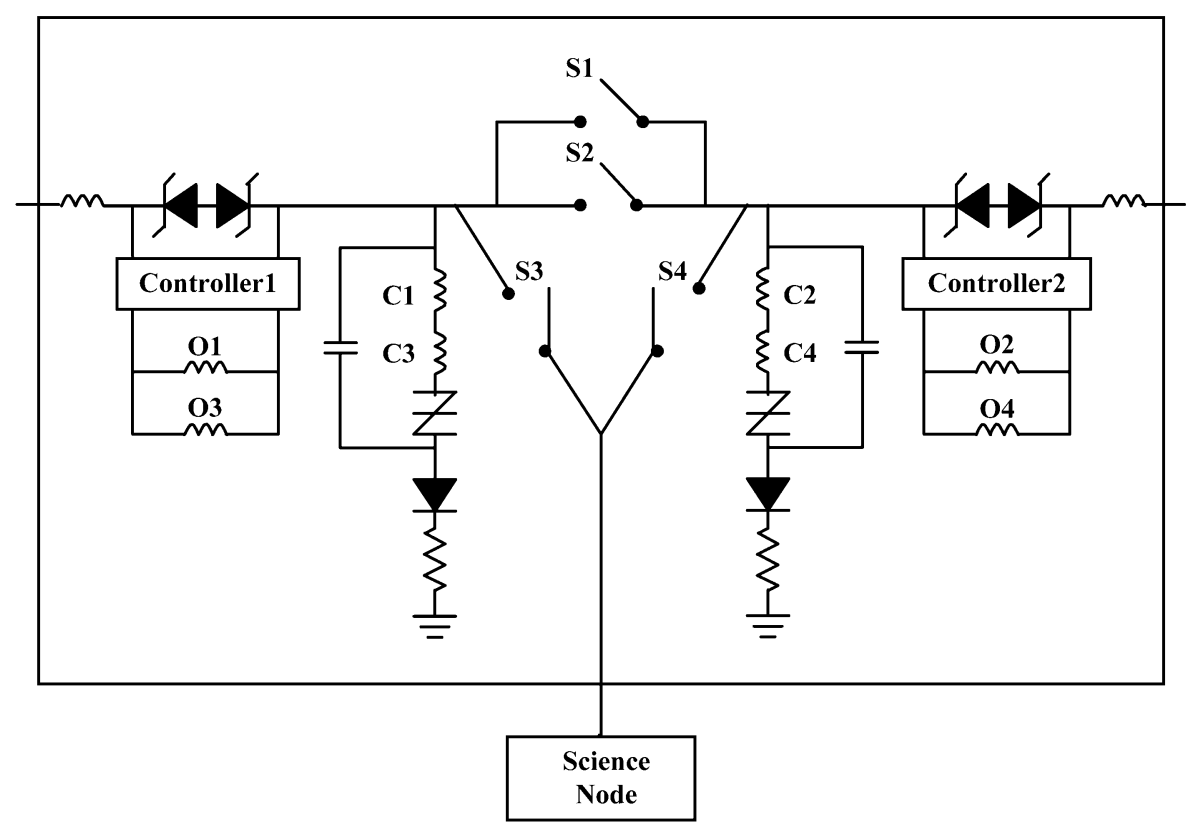

Fig. 7. BU of version 2 .

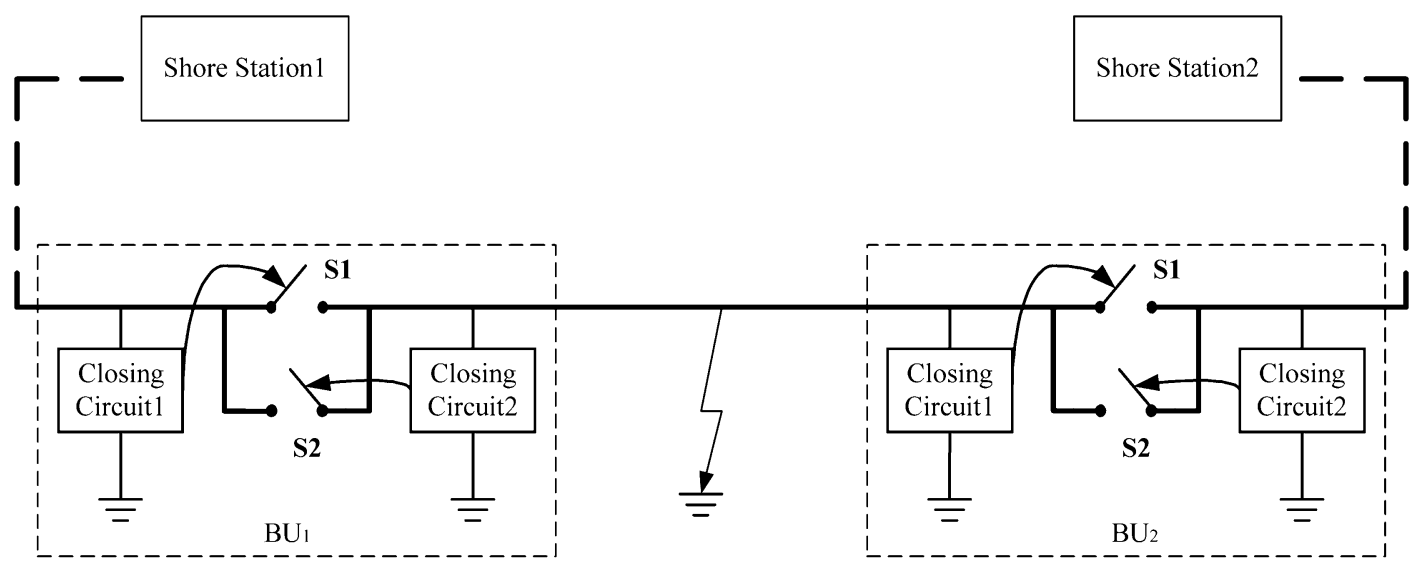

Fig. 8. Startup with faulted cable.

to charge. When the voltage across the capacitor reaches the break over voltage of the SIDAC, the capacitor discharges its energy into the closing solenoids $\mathrm{C} 1$ and $\mathrm{C} 3$; hence, $\mathrm{S} 1$ and $\mathrm{S} 3$ are closed. After $\mathrm{S} 1$ is closed, the right closing branch closes $\mathrm{S} 2$ and S4. Also, after S1 is closed, the power is provided to the next $\mathrm{BU}$, and the same closing procedure is repeated until all BUs are closed. The time required to close a single BU is approximately equal to the charging time of the capacitor through a section of the backbone cable plus the closing time of the vacuum switches. This total time is estimated to be about $500 \mathrm{~ms}$. Hence, to close 40 BUs of the entire system using two shore stations, the total time is about $10 \mathrm{~s}$. This is a relatively short period. Further, the energy loss of the charging resistance is small so that the charging resistance can be installed inside the BU with no need for cooling.

The NEPTUNE cable system is fully connected during the startup mode even if a fault exists before the startup operation. This is achieved by the network configuration of NEPTUNE cables, and the redundant switches in each BU. Fig. 8 shows two BUs closing on a faulted line. Assume that all the switches are initially open. Assume that $\mathrm{BU}_{1}$ is closed first by using closing circuit1 of switch S1. After the switch is closed, the voltage across the cable is dropped to a very low value and closing circuit2 cannot latch switch $\mathrm{S} 2$ of $\mathrm{BU}_{1}$. Furthermore, closing circuit 1 of $\mathrm{BU}_{2}$ cannot close its $\mathrm{S} 1$. However, the voltage on the side of closing circuit 2 of $\mathrm{BU}_{2}$ is high since we have two power stations and the cables are connected in network fashion. Hence, closing circuit2 of $\mathrm{BU}_{2}$ will close switch $\mathrm{S} 2$ and the faulted cable is connected.

After closing all the BU switches (and recall, there are no loads at this time), the shore station is disconnected, and its voltage is reversed. Then the shore station voltage increases gradually to the full negative voltage of $10 \mathrm{kV}$. The system is now fully connected and ready to serve the loads.

2) Faulted Mode: The PMACS system determines the presence of a fault by at least one of the following methods.

- The fault current is sensed at the shore stations if the fault is near shore.

- The nodes (science node) around the fault experience drop in voltages. Since PMACS monitors the node voltage, the 
presence of the fault can be determined and approximately located.

- If the node voltages drop to below the minimum required by the node main dc-dc converter $(5.2 \mathrm{kV})$, which powers the communication system, the measurements cannot be transmitted to PMACS. Hence, a combination of sensing and state estimation can be used to identify and locate the fault.

Once the fault is detected, the shore system goes into the fault locating mode.

3) Fault Locating Mode: The shore stations switch off the network. However, since the BU switches are latch vacuum interrupters, they remain closed. The shore stations then energize the system with a positive voltage of $500 \mathrm{~V}$. This is the communication signal from PMACS to the BU controller to keep all switches closed. Also because the voltage is positive, the closing circuits will ensure that all switches are closed. A separate module of PMACS uses an algorithm based on the known cable parameters to locate the fault using shore V/I measurements [7]. After a delay designed to allow for fault location by PMACS, the system enters into the fault isolation mode.

4) Fault Isolation Mode: In this mode, the section of the cable with the fault is isolated and the rest of the network maintained in normal operation. If the fault is in one of the backbone cables, all loads will be restored. If the fault is in one of the spur cables, only the load fed from the spur cable is isolated.

The system enters the fault isolation mode when the shore stations energize the system at a negative $500 \mathrm{~V}$ (less than the dc-dc converter turn-on voltage). This voltage level activates all BUs' controllers. The controller in each BU uses an isolation algorithm to determine if any switching action is needed by the $\mathrm{BU}$ to isolate the fault. The controller calculates the distance to the fault by using the locally measured V/I ratio, and opens the switches after a delay $T$, which is proportional to the distance of the BU from fault. Thus, the closer the BU is to the fault, the smaller the delay $T$ (which is specific to the location). Accordingly, the BUs on both ends of the faulted section open first and the fault is cleared. When the fault is cleared by the opening of a second (or third) breaker, the other BUs experience an increase in their voltage and (more importantly) a reduction in the current. This transition in voltage and current are to be interpreted by the other BU controllers as inhibiting signals for any switching action. Now the backbone cables are all connected except the faulted section.

The main function of a controller is to open its switches to clear an adjacent faulted cable section. The operational features of the controller include the following.

- Since the controller is powered through the zener diodes shown in Fig. 7, they are only active when a current is flowing in the backbone. In the fault isolation operation, if the fault current is not passing through a BU, its controller is not powered. Therefore, the BU switches are kept in the closing state.

- The controller is designed to allow the initial transients to bypass and only operates after the steady-state current is reached.
- In the normal operation, the controller will inhibit any switching action at $-10 \mathrm{kV}$.

After the faulted cable is repaired, which normally takes weeks or months, the shore stations start up the system as explained in Section II-B1.

\section{LABORATORY SETUP AND TESTS}

To validate Versions 1 and 2, prototypes were built in the Energy Laboratory of the Department of Electrical Engineering at the University of Washington.

\section{A. Prototype of Version 1}

The prototype is a $300-\mathrm{V}$ system with all the components described in Fig. 5. The vacuum interrupters are normally open single-pole single-throw switches rated at $12 \mathrm{kV}, 15 \mathrm{~A}$. The solenoids of the vacuum interrupters are rated at $12 \mathrm{~V}$. The equivalent impedance of the solenoid is $48 \Omega$. With four vacuum switches in the breaker, the driving circuit requires an auxiliary power supply of $12 \mathrm{~V}, 1 \mathrm{~A}$.

The release time of the interrupter is $3 \mathrm{~ms}$. The bypass capacitor is $500 \mathrm{~V}, 1 \mu \mathrm{F}$. The soft closing resistor is $1 \mathrm{k} \Omega$ rated at $500 \mathrm{~V}$.

The objective of this test is to check the logic circuit, the closing and opening sequence, and the durability of the vacuum interrupter for repeated switching. It is unlikely that restrikes would occur at such a low voltage. Higher voltage testing at $10 \mathrm{kV}$ will be our next step.

The breaker system was tested by running through all the stages of the breaker's operation as indicated in Sections II-A1 and II-A2. The load was kept at the rated value of the vacuum switches $(15 \mathrm{~A})$. The durability of the vacuum switches was tested by cycling through the different switching steps continuously once per second for a total of 125000 operations. All tests were successful in terms of functionality and heat buildup.

\section{B. Prototype of Version 2}

The switching circuit of version 2 was also built in the lab. The main objectives of the lab tests were: 1) to test the switching sequence and the circuit functionality; 2) to test the reliable operation of the circuit under very low voltage conditions to simulate conditions with nearby shorts; and 3) to test the circuit for durability.

In Fig. 9, the top figure shows the voltage across the capacitor. The lower figure shows the voltage across the closing solenoids of the vacuum switches. As seen in the figures, the capacitor is charged positively to the break over voltage of the SIDAC, $60 \mathrm{~V}$. Then after the SIDAC is closed, the energy stored in the capacitor is transferred to the solenoids, and the vacuum switches are closed. This test was repeated for various voltage levels, including as low as $60 \mathrm{~V}$. All backbone switches must be closed even at this low voltage level, to allow for the fault location mode. Judging from the various simulations for NEPTUNE backbone system, it seems that our test is conservative: the $60-\mathrm{V}$ level is below the actual voltage expected during fault conditions. 

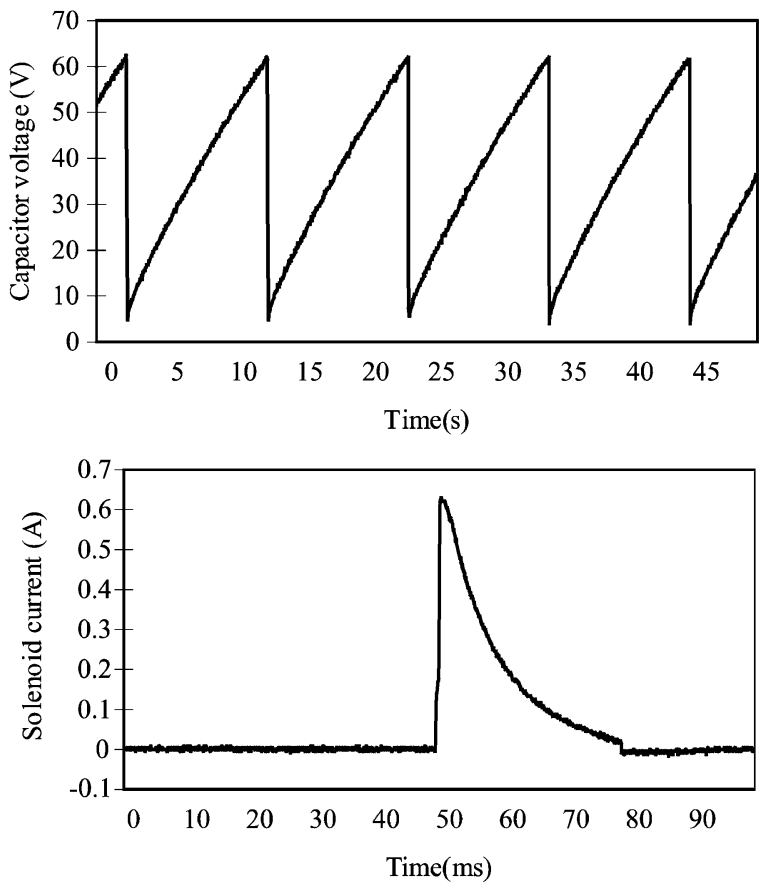

Fig. 9. Energy buildup and current of closing solenoids.

For the durability test, the circuit was continuously switching at a rate of 0.5 to $1 \mathrm{~Hz}$ for over $10 \mathrm{wk}$. This amounts to over 3 Xmillion switching operations so far. In NEPTUNE system, the circuit is not expected to operate more than a few times each year.

Overheating and missing operations were monitored during the test. The heating level is very low, and we estimate that the temperature rise in the BU will be small. No missing operation was detected during the entire testing period.

\section{CONCLUSION}

We have described a new switch-operating method that is proposed for the NEPTUNE power system. Simulations and prototype tests at low voltage suggest that the method will be simple and reliable, and that the temperature rise in the submerged branching unit will be acceptable.

We plan to review the method within the structure of the power group and, if the change is accepted, move to testing at a more realistic voltage level.

\section{REFERENCES}

[1] "Illuminating the hidden planet: the future of seafloor observatory science," National Academy National Research Council (NRC), Washington, DC, 2000.

[2] North east pacific time-integrated undersea networked experiments (NEPTUNE). [Online]. Available: http://www.neptune.washington.edu

[3] Real time, long term ocean and earth studies at the scale of a tectonic plate. NEPTUNE feasibility study. [Online]. Available: www.neptune.washington.edu

[4] B. M. Howe, H. Kirkham, and V. Vorperian, "Power system considerations for undersea observatories," IEEE J. Ocean. Eng., vol. 27, no. 2, Apr. 2002.

[5] M. A. El-Sharkawi, J. Xing, A. Rodriguez, and N. Butler, "Adaptive sequential controller for power system circuit breakers," U.S. Patent 5361 184, Nov. 1, 1994.
[6] - "Adaptive sequential controller with minimum switching energy," U.S. Patent 644 463, Jul. 1, 1997.

[7] K. Schneider, C. C. Liu, T. McGinnis, B. Howe, and H. Kirkham, "Realtime control and protection of the NEPTUNE power system," Oceans '02 MTE/IEEE, Aug. 2002.

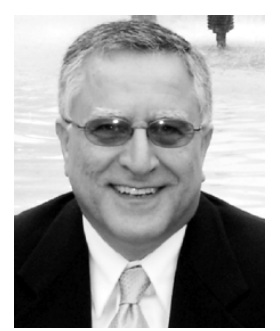

Mohamed A. El-Sharkawi (F'95) received the B.Sc. degree in electrical engineering in 1971 from Cairo High Institute of Technology, Egypt, and the Ph.D. degree, also in electrical engineering, from the University of British Columbia in 1980.

In 1980, he joined the University of Washington, Seattle, as a faculty member where he is currently a Professor of Electrical Engineering. He has published more than 200 papers and book chapters, in addition to two textbooks. He is the coeditor of several IEEE tutorial books and holds five patents.

Dr. El-Sharkawi is the Vice President of the IEEE Neural Networks Society. $\mathrm{He}$ is the founder and cofounder of several international conferences including the Application of Neural Networks to Power Systems (ANNPS), and Intelligent Systems Applications to Power (ISAP).

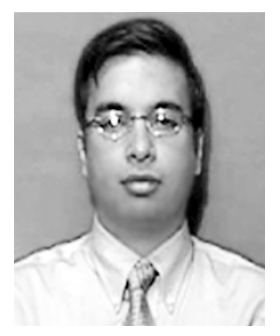

Aditya Upadhye was born in Thane, India, in 1980. He received the B.E. degree from the University of Pune, India, in 2001 and the M.S.E.E. degree from the University of Washington, Seattle, in 2003.

$\mathrm{He}$ is currently a member of the System Planning Group of ISO-New England, Inc., which is the bulk electric power system operator of the six states in New England. His interests include power system dynamics, protection, and short-circuit transient studies.

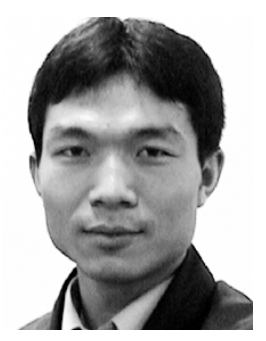

Shuai Lu was born in Luoyang, China, in 1976. He received the B.S.E.E. and M.S.E.E. degrees from Tsinghua University, China, in 1999 and 2002, respectively.

$\mathrm{He}$ is currently pursuing the Ph.D. degree in the Electrical Engineering Department, University of Washington, Seattle. His research interests include power electronics, power system control and neural networks applied to electrical power systems.

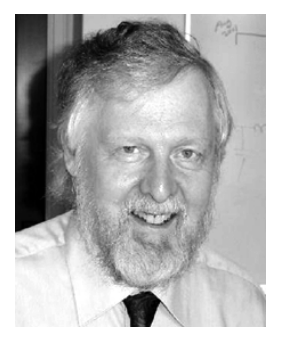

Harold Kirkham (SM'83-F'04) received the B.Sc. degree in 1966, and the M.Sc. degree in 1967, both from the University of Aston, Birmingham, U.K. He received the Ph.D. degree from Drexel University, Philadelphia, PA, in 1973.

In the late 1960s in Philadelphia, he worked on the AC/DC Research Project of the Edison Electric Institute, and continued an interest in the topic of combined ac/dc systems into his Ph.D. work. From 1973 until 1979, he was with American Electric Power, responsible for the data acquisition system at their UHV station in Indiana. In 1979, he joined the staff of the Communications and Control for Electric Power Systems project, Jet Propulsion Laboratory (JPL), Pasadena, CA. He managed the project from 1984 until it ended in 1995. $\mathrm{He}$ is presently a Principal in the Center for In-Situ Exploration and Sample Return at JPL. His research interests include both power and measurements. He has developed a series of instruments to measure electric fields. He is presently manager of the NEPTUNE power system project, a development being done in collaboration with the University of Washington.

Dr. Kirkham is the Chairman of the IEEE Power Engineering Society's Instrumentation and Measurements Committee. 


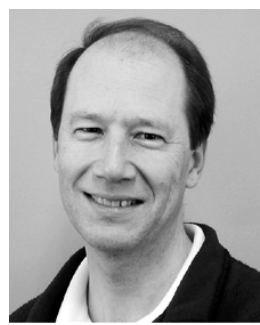

Bruce M. Howe received the B.S. and M.S. degrees in mechanical engineering and engineering science, respectively, in 1978 from Stanford University, Stanford, CA, and the Ph.D. degree in oceanography from the Scripps Institution of Oceanography, University of California, San Diego, in 1986.

While at Stanford University, he developed laser doppler velocimetry (LDV) instrumentation for air-sea interaction experiments. From 1979 to 1981, he was a Research Associate with the Institut für Hydromechanik, Universität Karlsruhe, Germany, working on LDVs for use in the atmospheric boundary layer. While at Scripps Institution and since then, he has worked on ocean acoustic tomography, most recently on the Acoustic Thermometry of Ocean Climate (ATOC) project. A current interest is cabled seafloor observatories, specifically the NEPTUNE project focused on the Juan de Fuca Plate. He is presently a Principal Oceanographer with the Applied Physics Laboratory and a Research Associate Professor with the School of Oceanography, both at the University of Washington, Seattle (http://www.apl.washington.edu/Research/OA/bruce_howe.html).

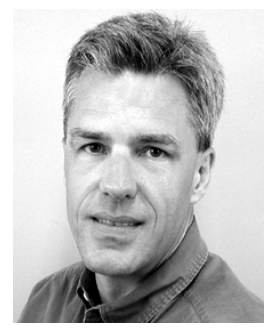

Tim McGinnis received the B.S.E. degree from the University of Washington, Seattle, in 1983.

$\mathrm{He}$ is a Senior Engineer with the Applied Physics Laboratory, University of Washington. His research interests include development of deep ocean instrumentation, robotics, and sampling equipment.

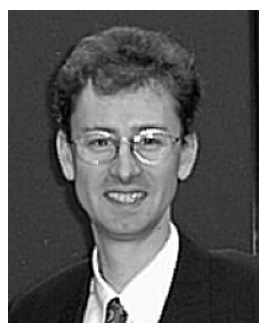

Phil Lancaster joined the Alcatel Optical Networks, London, U.K., in 1988. He is the Electrical/Software Development Leader for the Alcatel Power Feeding Equipment. He has worked on a range of different areas within submarine telecomms. His main area of expertise is in the development of DC power feeding systems. He has also been involved in the development of underwater branching units and repeaters. 